\title{
Redefining Unusable Weeds to Beneficial Plants: Purslane as a Powerful Source of Omega-3 for the Future
}

\author{
Rania Agil ${ }^{1}$, Chloé Gilbert ${ }^{1}$, Hamed Tavakoli ${ }^{1}$ \& Farah Hosseinian ${ }^{1,2}$ \\ ${ }^{1}$ Food Science and Nutrition, Chemistry Department, Carleton University, Ottawa, Ontario, Canada \\ ${ }^{2}$ Institute of Biochemistry, Carleton University, Ottawa, Ontario, Canada \\ Correspondence: Farah Hosseinian, Food Science and Nutrition, Chemistry Department \& Institute of \\ Biochemistry, Carleton University, Ottawa, Ontario, Canada. Tel: 1-613-520-2600, ext. 2048. E-mail: \\ farah_hosseinian@carleton.ca
}

Received: September 3, 2015 Accepted: September 21, 2015 Online Published: November 3, 2015

doi:10.5539/jfr.v4n6p39

URL: http://dx.doi.org/10.5539/jfr.v4n6p39

\begin{abstract}
With global consumer demand shifting towards the consumption of healthier foods, it is crucial to discover new sources of edible plants with high nutritional value and low cost. Unique weeds such as purslane have the potential to be used as an untapped source of unconventional food with diverse nutrients and beneficial bioactive properties. Inflammation can cause oxidative stress related diseases including cardiovascular disorders, aging and cancer. One key nutrient of purslane is omega-3 with potential of inhibitory properties against inflammatory and estrogenic mediators. Purslane is known to be a rich source of $\alpha$-linolenic acid, 18:3 $\omega$ - 3 , an essential fatty acid, carotenes, antioxidants and minerals. However, the precise mechanism of action of its individual components in disease prevention is unknown. This review provides a summary on the role of purslane bioactives, particularly omega-3 fatty acids as one of purslane's main constituents with potential of anti-inflammatory and anti-estrogenic properties. The discovery of new sources of plants rich in omega-3 fatty acids may be a useful strategy in utilizing natural alternative sources of foods that can enhance human health and wellbeing.
\end{abstract}

Keywords: Purslane, omega-3 Fas, $\alpha$-linolenic acid (ALA), anti-inflammatory action, Anti-estrogenic action, Antioxidant activity, health and wellbeing

\section{Introduction}

\subsection{Plant Description}

Purslane (Portulaca oleracea L.) has fleshy scrumptious leaves and yellow flowers (Figure 1). Purslane is annually reproducing itself from its seeds and stem parts as reported by (Simopoulos et al., 2005). The cotyledons (seed leaves) are egg shaped to oblong, hairless, succulent, about $1 / 13$ to $1 / 5$ inch (2-5 mm) long. Seeds are tiny, less than $1 / 25$ of an inch $(1 \mathrm{~mm})$ in diameter, circular to egg shaped, flattened, and brown to black with a white point of attachment (Simopoulos et al., 2005). Although purslane is considered a weed in North America, it is consumed as a vegetable in other parts of the world, especially in Europe, Asia, and the Mediterranean region (Zhou et al., 2015; Uddin et al., 2014). 


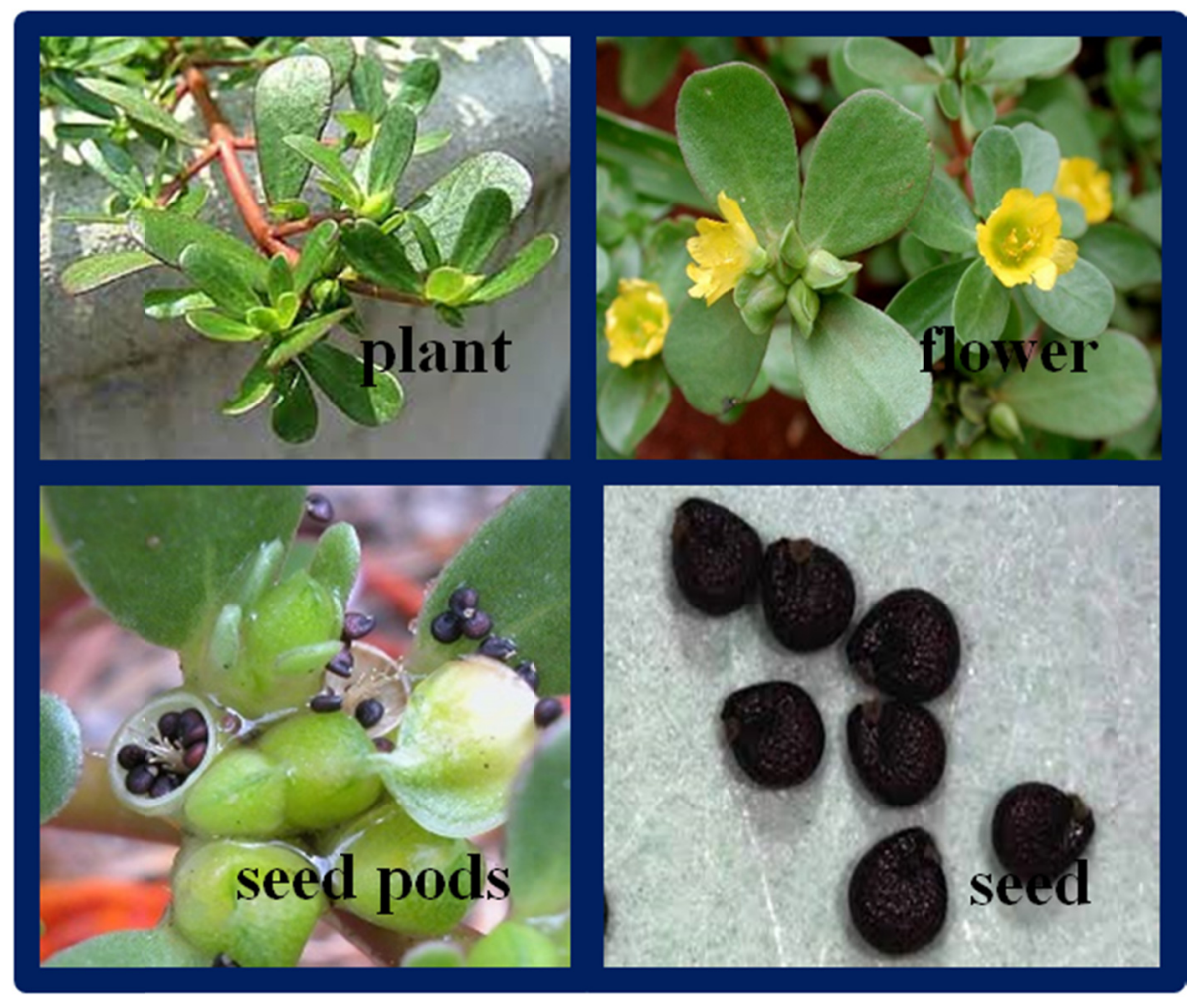

Figure 1. Purslane (Portulaca oleracea), adapted from (Simopoulos et al., 2005)

\subsection{Purslane Uses and Health Benefits}

Purslane is an ideal dietary green leafy vegetable having very low calories $(16 \mathrm{kcal} / 100 \mathrm{~g})$ and fats $(0.1$ to $0.5 \%)$ as reported by (Uddin et al., 2014). Purslane has a high nutrient density as reported by (Simopoulos et al., 2005; Uddin et al., 2014; Amirul Alam et al., 2014; Liang et al., 2014) and it contains a diverse array of nutrients that range from simple minerals, vitamins, and polysaccharides to complex fatty acids as well as phytochemicals such as flavonoids, alkaloids, terpenoids and sterols. Results in the literature (Uddin et al., 2014; Liu et al., 2000; Teixeira et al., 2010) have been shown that purslane is known to be a rich source of $\alpha$-linolenic acid, 18:3 $\omega-3$, an essential fatty acid, carotenes, and antioxidants. It is a rich source of potassium $(494 \mathrm{mg} / 100 \mathrm{~g})$ followed by magnesium $(68 \mathrm{mg} / 100 \mathrm{~g})$ and calcium $(65 \mathrm{mg} / 100 \mathrm{~g})$ in terms of mineral content. Additionally, it has been used in traditional medicine for its neuroprotective, antimicrobial, antidiabetic, antioxidant, anti-inflammatory and anticancer properties as reported by (Chan et al., 2000; Ellulu et al., 2015). Meanwhile, the precise role and mechanism of action of its individual constituents in disease prevention is unknown. This review provides a summary on the role of omega-3 fatty acids as one of purslane's main constituents with potential of anti-inflammatory and anti-estrogenic properties.

\subsection{General Classification of Omega-3 Fatty Acids and Their Conversion}

Omega-3 fatty acids/FAs, also known as polyunsaturated fatty acids (PUFAs) are essential FAs. They are necessary for human health but the body cannot synthesize and produce them on its own. Therefore omega-3 FAs must be consumed from dietary sources as reported by (Koh et al., 2015). Three main types of omega-3 FAs are involved in the human body are: $\alpha$-linolenic acid (ALA) (found in plant oils), eicosapentaenoic acid (EPA) and docosahexaenoic acid (DHA) (both commonly found in marine oils) as previously reported by (Chan et al., 2000; Ellulu et al., 2015). Flaxseed oil, canola oil and walnut oil are common plant-based sources of ALA omega-3 fatty acids. In contrast, linoleic acid (LA) is an omega-6 fatty acid which can mainly be found in corn oil, soybean oil, sunflower oil and safflower oil, evening primrose oil and borage oil. $\Delta^{6}$ desaturases enzymes are required for the synthesis of unsaturated omega-6 and omega-3 FAs (Figure 1). In a multi-stage process, elongase and desaturase enzymes synthesize EPA and DHA from linolenic and arachidonic acid. (Chan et al., 2000; Ellulu et al., 2015) reported the recommended daily intake of omega- 6 is between 3.0 to 4.4 (g/day) while for omega-3 FAs is 1.8 to 
2.0 (g/day) or an omega-6/omega-3 ratio of about 4:1. Meanwhile, the daily intake of combination EPA and DHA is 0.66 (g/day) recommended by (Koh et al., 2015).

\subsection{Omega-3 in Purslane and Bioactivity}

Omega-3 FAs have been shown to reduce inflammation and may help lower risk of chronic diseases such as heart disease, cancer, and arthritis. Omega-3 FAs shown to improve human brain function and mood and thus having neuroprotective properties (Ellulu et al., 2015; Koh et al., 2015). Purslane is good sources of ALA as reported in literatures (Simopoulos, A.P. et al., 2005; Uddin, M.K. et al., 2014). The total fatty acid content in purslane ranged from 2.1 to $3.7 \mathrm{mg} / \mathrm{g}$ of fresh leaves, 0.6 to $0.9 \mathrm{mg} / \mathrm{g}$ in stems and 80.7 to $185.1 \mathrm{mg} / \mathrm{g}$ in seeds (Table 1) (Simopoulos et al., 2005; Uddin et al., 2014). Overall, ALA accounted for approximately $40 \%$ and $60 \%$ of the total fatty acid content in seeds and leaves, respectively (Table 1). Purslane's fresh leaves contain remarkably more ALA than any other leafy vegetable plant. Cabbage, cauliflower, broccoli and spinach contain a small (0.02 to 0.1 $\mathrm{g} / 100 \mathrm{~g}$ fresh weight) level of omega-3 FAs (Simopoulos et al., 2005; Uddinet al., 2014). In addition, a 100g serving of fresh purslane will provide about 20 grams of polyunsaturated fatty acids (PUFAs). In fact, purslane is one of the best sources of omega-3 FAs for vegetarians. Ultimately, in all parts of purslane including the leaves, stems and seeds, PUFAs were found to be most abundant, followed by saturated fatty acids (SFAs) and monounsaturated fatty acids (MUFAs) (Table 1).

Table 1. Fatty acid contents (mg/g) in purslane leaves and seeds; adapted from (Uddin et al., 2014)

\begin{tabular}{|c|c|c|}
\hline Fatty acid & Seeds & Leaves \\
\hline $14: 0$ & $0.2-0.3$ & $0.05-0.09$ \\
\hline $16: 0$ & $14.0-23.7$ & $0.3-0.4$ \\
\hline 18:0 & $2.7-6.8$ & $0.07-0.1$ \\
\hline Total ${ }^{1}$ SFA & $16.7-30.5$ & $0.1-0.2$ \\
\hline 18:1 & $8.6-19.0$ & $0.05-0.15$ \\
\hline Total ${ }^{2}$ MUFA & $8.6-19.0$ & $0.05-0.15$ \\
\hline $18: 2$ & $28.2-54.7$ & $0.1-0.3$ \\
\hline $18: 3$ & $26.7-68.8$ & $1.0-1.6$ \\
\hline $20: 5$ & nd & nd \\
\hline $22: 6$ & *nd & nd \\
\hline Total ${ }^{3}$ PUFA & $55.0-113.5$ & $1.1-3.4$ \\
\hline Total & $80.7-185.1$ & $2.1-3.7$ \\
\hline
\end{tabular}

${ }^{1}$ saturated fatty acids

${ }^{2}$ monounsaturated fatty acid

${ }^{3}$ polyunsaturated fatty acids

*nd=not detected

Although earlier studies showed the presence of EPA (0.8-12.6) and DHA (0.3-6.4) in purslane leaves and seeds using GC (Simopoulos et al., 1995; Simopoulos et al., 1992) but this theory was not accepted later by (Liu et al., 2000), since the confirmation of chemical identity was not undertaken MS. Peaks with retention times corresponding to EPA and DHA were found by GC but they were not confirmed by MS (Liu et al., 2000). This author reported the total fatty acid content that determined by GC-MS, ranged between 1.5 to $2.5 \mathrm{mg} / \mathrm{g}$ in fresh leaves, 0.6 to $0.9 \mathrm{mg} / \mathrm{g}$ in stems and 80 to $170 \mathrm{mg} / \mathrm{g}$ in seeds. The ALA acid was the predominant fatty acids, counting for approximately $60 \%$ in leaves and $40 \%$ in seeds of the total fatty acid content, respectively. The beta-carotene content ranged between 22 to $30 \mathrm{mg} / \mathrm{g}$ in fresh leaves. The author concluded that Australian purslanes are a rich source of ALA acid and beta-carotene (Liu et al., 2000). Omega-3 fatty acid desaturase genes isolated from purslane in different tissues to cold and wound stress studied by (Teixeira et al., 2010) showed that the total fatty acid and linolenic acid content were higher in both wounded and intact leaves of plants exposed to low temperature due to the higher activity of fatty acid desaturase enzymes (Teixeira et al., 2010). HPLC was reported by (Xin et al., 2008) to be reliable and simple method to determine ALA and linoleic acid in purslane using a Shim-pack CLC-ODS (250 mm x $4.6 \mathrm{~mm}, 5$ microm) and a DIKMA Easyguard C18 (10 mm x $4.6 \mathrm{~mm})$ columns and methanol:acetonitrile: $0.5 \%$ phosphonic acid (60:22:18) at flow rate of $1.1 \mathrm{ml} / \mathrm{min}$. Alpha-linolenic acid $(0.0162$ to $0.1944 \mathrm{mg} / \mathrm{ml})$ and linoleic acid $(0.0169$ to $0.2030 \mathrm{mg} / \mathrm{ml})$ were detected at wavelength of 210 $\mathrm{nm}$. A summary of purslane health benefits is shown in (Table 2). The majority of these health benefits could be 
due to the anti-inflammatory effects of purslanes.

Table 2. Health benefits of purslane in vivo and in vitro

\begin{tabular}{|c|c|c|c|}
\hline $\begin{array}{l}\text { Selected materials } \\
\text { used }\end{array}$ & Objectives & Results & Reference \\
\hline $\begin{array}{l}\text { Purified a unique } \\
\text { polysaccharide } \text { from } \\
\text { whole purslane }\end{array}$ & Anti-tumor effects in vivo in rats model & $\begin{array}{l}\text { Enhanced animal's immune responses } \\
\text { including an increase in the number of white } \\
\text { blood cell (WBC) and CD4(+) Tlymphocytes }\end{array}$ & Shen, $2013 \# 176\}$ \\
\hline $\begin{array}{l}\text { Ethanolic extract of } \\
\text { the aerial parts (dried } \\
\text { leaves and stem }\end{array}$ & $\begin{array}{l}\text { Anti-inflammatory properties compared } \\
\text { with the synthetic drug, diclofenac sodium } \\
\text { as the active control in mice model }\end{array}$ & Relief of pain and inflammation & $\begin{array}{l}\text { (Chan, K. et al., } \\
2000)\end{array}$ \\
\hline $\begin{array}{l}\text { High dose and low } \\
\text { dose of Omega-3 from } \\
\text { purslane } \quad \text { for } \\
\text { eight-week }\end{array}$ & $\begin{array}{l}\text { Anti-inflammatory cell effect on } \\
\text { modulation of TIMPs, TGFs, and MMPs in } \\
\text { vivo in mice model }\end{array}$ & $\begin{array}{l}\text { Higher TIMP- } 1 \text { and TGF-betal stain intensity } \\
\text { in mice fed the high, compared to the low } \\
\text { Omega- } 3 \text { diet. MMP- } 2 \text { immunoreactivity was } \\
\text { unaffected by diet }\end{array}$ & $\begin{array}{l}\text { (Kavazos, K. et } \\
\text { al., 2015) }\end{array}$ \\
\hline $\begin{array}{l}\text { An aqueous extract of } \\
\text { purslane leaves and } \\
\text { stems }\end{array}$ & $\begin{array}{l}\text { Prevention of TNF-alpha-induced vascular } \\
\text { inflammatory process in the human } \\
\text { umbilical vein endothelial cell (HUVEC) }\end{array}$ & $\begin{array}{l}\text { Inhibiting the vascular inflammation process } \\
\text { was observed by anti-TNF-alpha activity of } \\
\text { purslane in human Vascular Endothelial Cells, } \\
\text { inhibition of intracellular ROS production and } \\
\text { NF-kappaB activation }\end{array}$ & $\begin{array}{l}\text { (Lee, A.S. et al., } \\
\text { 2012) }\end{array}$ \\
\hline $\begin{array}{l}\text { An aqueous extract of } \\
\text { purslane leaves and } \\
\text { stems }\end{array}$ & $\begin{array}{l}\text { anti-inflammation and anti-allergy by } \\
\text { human epithelial cell apoptosis }\end{array}$ & $\begin{array}{l}\text { Protective effect on UVB-induced damage in } \\
\text { human epithelial keratinocytes and fibroblasts } \\
\text { by several apoptosis-related tests }\end{array}$ & $\begin{array}{l}\text { (Lee, S. et al., } \\
2014)\end{array}$ \\
\hline Aqueous seed extracts & $\begin{array}{l}\text { Cytotoxicity assessments on human } \\
\text { hepatocellular carcinoma cells (HepG2) in } \\
\text { vitro }\end{array}$ & $\begin{array}{l}\text { Reduced the cell viability of HepG2 in a } \\
\text { concentration dependent manner by } \\
\text { 3-(4,5-dimethylthiazol-2yl)-2,5-biphenyl } \\
\text { tetrazolium bromide (MTT) assay and neutral } \\
\text { red uptake (NRU) assay. }\end{array}$ & $\begin{array}{l}\text { (Farshori, N.N. et } \\
\text { al., 2014) }\end{array}$ \\
\hline Whole purslane & $\begin{array}{l}\text { Hypoglycemic and antioxidant activities } \\
\text { in insulin-resistant HepG2 cells and } \\
\text { streptozotocin-induced } \mathrm{C} 57 \mathrm{BL} / 6 \mathrm{~J} \text { diabetic } \\
\text { mice in vivo }\end{array}$ & $\begin{array}{l}\text { Possessed antidiabetic activities by } \\
\text { significantly enhanced insulin secretion and } \\
\text { antioxidative activities by preventing } \\
\text { formation of malondialdehyde (MDA) and } \\
\text { increasing the superoxide dismutase (SOD) } \\
\text { activity }\end{array}$ & $\begin{array}{l}\text { (Gu, J.F. et al., } \\
2015)\end{array}$ \\
\hline $\begin{array}{l}\text { Purslane } \\
\text { polysaccharides }\end{array}$ & $\begin{array}{l}\text { Evaluation of antioxidant and } \\
\text { immuno-enhancing activities in on the } \\
\text { oxidative injury and immune status in } \\
\text { N-methyl-N'-nitro-N-nitrosoguanidine } \\
\text { (MNNG)-induced gastric cancer rats }\end{array}$ & $\begin{array}{l}\text { A dose-dependent protection against } \\
\text { MNNG-induced oxidative injury by } \\
\text { enhancing SOD, CAT, GSH-Px antioxidant } \\
\text { activities of gastric cancer rats. }\end{array}$ & $\begin{array}{l}(\mathrm{Li}, \quad \mathrm{Y} \text {. et al., } \\
2014)\end{array}$ \\
\hline $\begin{array}{l}\text { Phenolic extracts from } \\
\text { purslane leaves, } \\
\text { flowers and stems }\end{array}$ & $\begin{array}{l}\text { antioxidant activity assays including } \\
\text { 1,1-diphenyl- 2-picryl-hydrazyl (DPPH) } \\
\text { radical, total phenolic content and } \\
\text { ferric-reducing antioxidant power }\end{array}$ & $\begin{array}{l}\text { All parts of plant showed protective effects } \\
\text { against DPPH radical and inhibitory effect on } \\
\text { hydrogen peroxide-induced lipid and } \\
\text { peroxidation on DNA against hydroxyl } \\
\text { radicals }\end{array}$ & $\begin{array}{l}\text { (Silva, R. et al., } \\
\text { 2014) }\end{array}$ \\
\hline
\end{tabular}

\subsection{Other Bioactives in Purslane}

Purslane possesses a wide spectrum of other bioactive compound such as flavonoids, alkaloids, polysaccharides, terpenoids, sterols, proteins, vitamins and minerals with antimicrobial, antidiabetic, antioxidant, anti-inflammatory, and anticancer properties (Zhou et al., 2015). However, few molecular mechanisms of action are known. Phenolic alkaloids such as three oleraceins was reported by (Yang et al., 2009) as a new class of antioxidants in purslane, showing a higher DPPH radical scavenging activity than ascorbic acid and alpha-tocopherol. Alpha-tocopherol, ascorbic acid, beta-carotene and glutathione in leaves of purslane exhibited higher amount than did in spinach (Simopoulos et al., 1992). Purification and characterization of an antitumor polysaccharide from purslane in rats model studied by (Shen et al., 2013) showed that purslane enhanced animal's immune responses including an increase in the number of white blood cell (WBC) and CD4(+) Tlymphocytes. Anti-inflammatory properties of ethanolic extract of phenolics from the aerial parts (dried leaves and stem) was compared with the synthetic drug, diclofenac sodium as the active control in mice model for eight 
weeks by (Chan et al., 2000) and showed rats were relieved of pain and inflammation. An aqueous extract of purslane leaves and stems was used by (Lee et al., 2012) to see if they can prevent TNF-alpha-induced vascular inflammatory processes in the human umbilical vein endothelial cell (HUVEC). Results showed an inhibition of vascular inflammatory processes via anti-TNF-alpha activity, inhibition of intracellular ROS production and NF-kappaB, by purslane in human Vascular Endothelial Cells (Lee et al., 2012). Table 2, shows some of the bioactivities.

\subsection{Anti-Inflammatory Mechanism of Action}

Phospholipases act on phospholipids to produce precursor molecules for a variety of pathways including the arachidonic acid metabolic pathway (Cotran, 2010). Meanwhile, there are a number of different phospholipases (A, B, C, D), each having a specific preference for a specific type of phospholipid in the membrane, creating slightly different products. The type of product can then act as a pro-inflammatory mediator or an anti-inflammatory mediator (Ellulu et al., 2015; Koh et al., 2015). When omega-3 FAs from purslane are ingested, they can be acted upon by one particular type of phospholipase that prefers them. As a result of a different phospholipase acting on omega-3 FAs, there will also be a different type of product produced (Cotran, 2010). Thus the particular products formed only upon ingestion of omega-3 FAs from purslane may have potential health benefits for inflammatory, metabolic, and even genetic disorders such as cancer (Ellulu et al., 2015; Koh et al., 2015). Eicosanoids are one of the many mediators of inflammation examples of which include prostaglandins, prostacyclin, thromboxane, and leukotrienes (Figure 2) (Cotran, 2010). These are all byproducts of the arachidonic acid (AA; 20:4 $\omega-6$ or eicosatetraenoic acid) oxidation pathway (Varma et al., 2010). Two principal enzymes within the arachidonic acid oxygenation pathway are the cyclo-oxygenases (COX1 and COX2) which produce prostaglandins (PGs) and the 5-lipoxygenase (LOX) which produces leukotrienes (LTs) (Chan et al., 2000). Meanwhile, while some specific prostaglandins are anti-inflammatory, others are inflammatory and the key is to find the balance and target a particular type for stimulation or inhibition in order to treat disease. The human body has to continually use essential fatty acids (EFAs) in order to convert them to prostaglandins whether pro or anti-inflammatory and thus an improper balance can lead the pathway in either direction. With essential fatty acids being the focal molecule for this pathway, the omega-3 in purslane plays a crucial role in providing the specific type of essential fat that can be used as a precursor and consequently result in either pro or anti-inflammatory prostaglandins as reported by (Chan et al., 2000; Cotran, 2010). Under physiological conditions, the body converts LA (e.g. from corn or sunflower oil) into $\gamma$-linolenic acid (GLA) and converts ALA (e.g. from purslane) into EPA. ALA and EPA are then converted to prostaglandin PGE1 and PGE3 which are in fact anti-inflammatory prostaglandins (Figure 2) (Cotran, 2010). Meanwhile, diets high in saturated and hydrogenated fats are normally high in omega- 6 FAs and they result in greater production of PGE2 (pro-inflammatory) and a reduced production of PGE1 and PGE3 (both anti-inflammatory) (Figure 2). On the other hand, diets rich in omega-3 FAs (e.g. purslane), result in the production of less PGE2 while enhancing the levels of PGE1 and PGE3.

One potential mechanism of action for anti-inflammatory properties of omega-3 FAs (e.g. omega-3 in purslane) is that they get inserted in membrane phospholipids and become a substitute and thus compete with other fatty acids for the same enzymes in eicosanoid and arachidonic acid production (Cotran, 2010). As a result the arachidonic acid produced could have a different type of fatty acid in its core architecture one that can have more double bonds or less, something that will also eventually determine the destiny of the future prostaglandins that are going to be derived from it. The type of prostaglandin produced or at least increased or decreased has a critical role in determining the direction that a large variety of biological activities are going take especially those concerned with the clotting cascade, platelet aggregation, vasodilation, neutrophil migration, bronchospasm, and pain (Cotran, 2010). While PGE2 is one of the key prostaglandins with significant pro-inflammatory effects, omega-3 FAs on the other hand can result in a reduction in PGE2 by having the enzyme use a different precursor for its activities (Varma et al., 2010). In addition, omega-3 FAs (e.g. omega-3 in purslane) also have inhibitory effects on the actions of 5-lipoxygenase, which is responsible for the synthesis of many pro-inflammatory leukotrienes. Furthermore, omega-3 FAs also recruit other anti-inflammatory mediators especially lipoxins.

A study of magnetic resonance spectroscopy conducted by (Varma et al., 2010) assessed the effects of fatty acids on inflammatory bowel disease in Sprague-Dawley rats. The fatty acids studied were: high-fat beef tallow (saturated fatty acids), high-fat corn oil (omega-6) and high-fat flaxseed oil (omega-3). Initially, half of the animals were fed $2 \%$ carrageenan to induce colonic inflammation. The study showed that high-fat corn oil had the most inflammatory effects and high-fat flaxseed oil the least (Varma et al., 2010). In addition, antidiabetic activity of purslane seeds studied by (El-Sayed, M.I. 2011) on subjects with type-2 diabetes, receiving $5 \mathrm{~g}$ of 
purslane seeds or $1,500 \mathrm{mg}$ of metformin/day showed remarkable hypoglycaemic, hypolipidaemic and insulin resistance reducer effects that could be possibly due to the polyunsaturated fatty acids in purslane seeds (El-Sayed, 2011). The ethanolic extract of purslane dried leaves and stems reported by (Chan et al., 2000) showed to have a significant anti-inflammatory action when compared with the control synthetic anti-inflammatory drug diclofenac sodium. Therefore, these studies indicate purslane can be used as a natural source of anti-inflammatory agent (Chan et al., 2000).

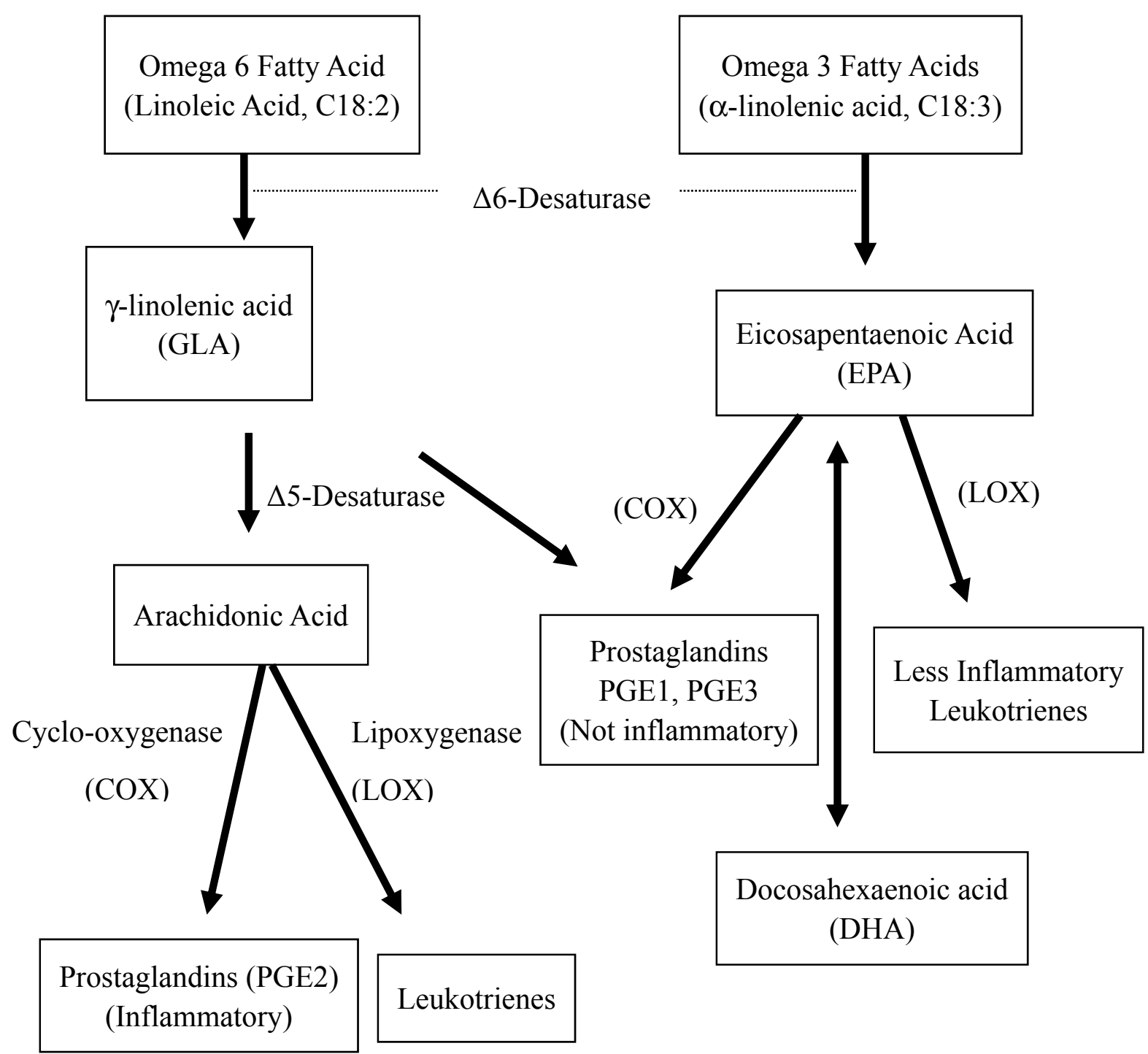

Figure 2. Generation of arachidonic acid metabolites and their role in inflammation (Cotran, 2010)

\subsection{Anti-Estrogenic Action of Omega-3 FAs}

Estrogen hormones play important roles in growth, development, reproduction, and maintenance in a variety of mammalian tissues. Estrogens are three biochemically distinct molecules the body produces naturally and they include estrone (E1), estradiol (E2), and estriol (E3) (Sturgeon et al., 2010). There is no report in the literature on anti-estrogenic activity of omega-3 from purslane. However, the omega-3 in purslane may have an anti-estrogenic effect similar to those reported from other food sources of omega-3. A tentative mechanism of purslane omega-3 and oxidative metabolism of estradiol is shown in (Figure 3). These three estrogens have different activities that make them more or less "estrogenic." Estradiol is the major biologically active estrogen in women. Excessive amounts of estrogen can increase the risk for hormone sensitive cancers such as breast or ovarian cancers (Sturgeon et al., 2010). Estradiol is the major estrogen that can be metabolized to estrone (a 
weaker estrogen), or to 2-hydroxyestrogen, 4-hydroxyestroge and 16-alpha-hydroxyestrogen (catechol form of estrogens) (Truan et al., 2010). Although 4-hydroxyestroge is carcinogenic it is produced in smaller concentrations and therefore, has less impact on cancer risk. The 16-alpha-hydroxyestrogen on the other hand is very estrogenic and it has a strong binding capacity with proteins in estrogen sensitive cells, especially proteins that play major roles at the genetic level and in cell proliferation and synthesis. Studies have shown that women with breast cancer have 50\% more of the 16-alpha-hydroxylation form of estrogen than healthy women. Meanwhile, the 2-hydroxyestrogen is an inactive form of estrogen it is considered to be "anti-estrogenic" and in fact, it has been shown to inhibit the growth of breast cancer cells (Truan et al., 2010). The liver enzymes that promote 2-hydroxyestrogen formation are inducible by diet (e.g. omega-3 in purslane). A higher ratio of 2-hydroxyestrogen to 16-alpha-hydroxyestrogen has been linked to a decrease in breast cancer risk (Sturgeon et al., 2010) and omega-3 fatty acids have shown to increase this ratio $(2 \mathrm{OH} / 16 \mathrm{OH})$. This same estrogen ratio can be used to assess anti-estrogenic effects of purslane since it is a major source of omega-3. Additionally, omega-3 FAs showed to decrease the protein binding capabilities of estradiol to proteins such as sex hormone binding globulin (SHBG) and intracellular receptors which are involved in gene expression and thus reduce their abilities to stimulate the growth of cancer cells. In contrast, omega-6-fatty acids (linoleic and arachidonic acid) inhibit the 2-hydroxylation of estrogen, and instead increase the 16-alpha-hydroxylated form (Sturgeon et al., 2010). Further research can provide more evidence for this theory which can also be promising practically.

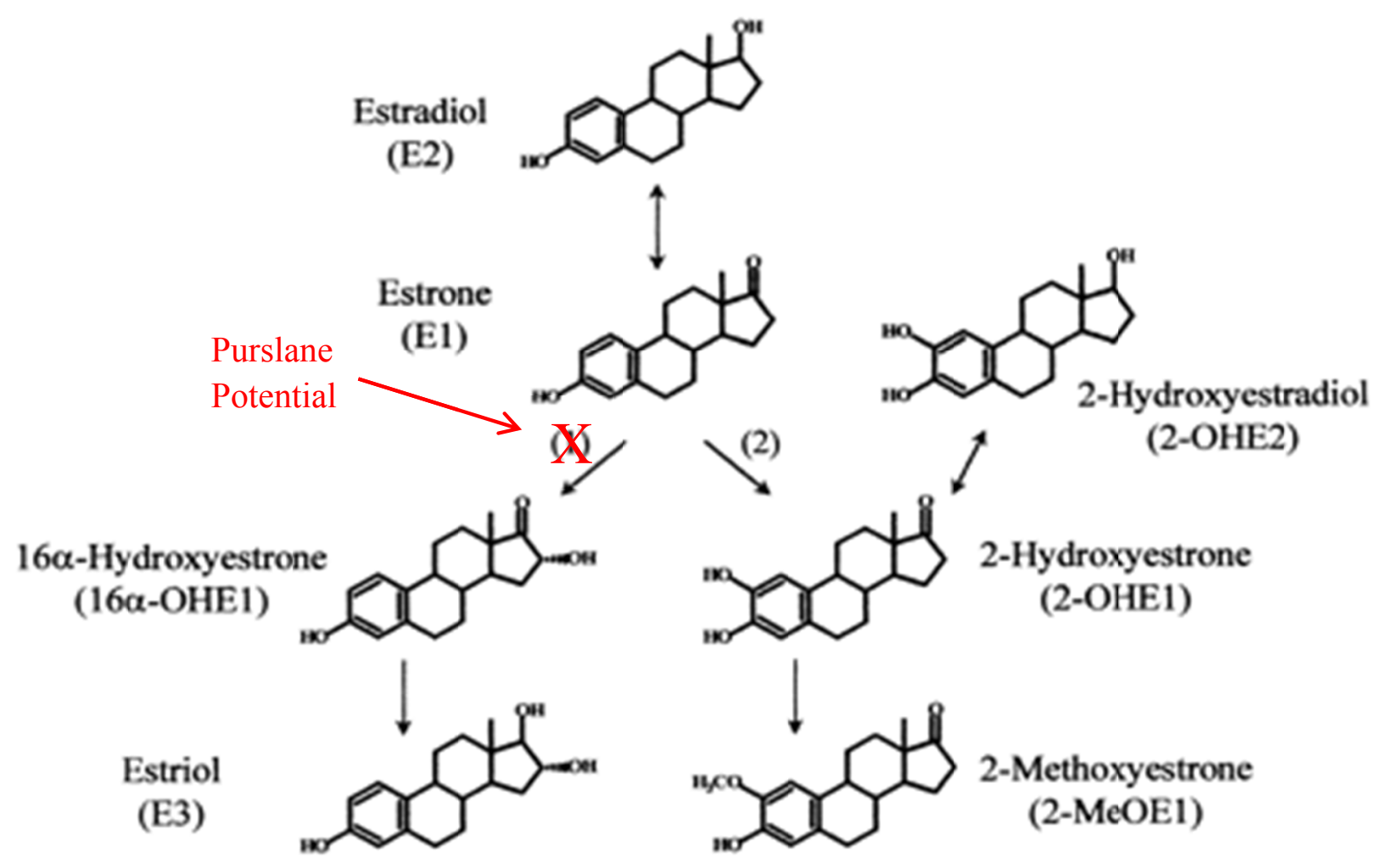

Figure 3. Oxidative metabolism of estradiol (Sturgeon et al., 2010)

\section{Conclusions}

With the limited number of commercially available plants containing omega-3 FAs, it is crucial to find new sources of unconventional plants high in omega-3 with inhibition properties against inflammatory and estrogenic mediators. This may be a useful strategy in utilizing natural alternative sources of omega- 3 with the potential of preventing inflammatory and estrogenic related disorders. Purslane has a great potential to become a new ready-to-use vegetable and as a result one of the best sources of omega-3 FAs among green leafy vegetables. In addition, purslane can be grown in diverse environments without the use of environmentally hazardous pesticides. Further research can help introduce this valuable vegetable in Canada as an excellent source of 
omega-3 in food and pharmaceutical applications.

\section{References}

Amirul Alam, M., Juraimi, A. S., Rafii, M. Y., Hamid, A. A., Kamal Uddin, M., Alam, M. Z., \& Latif, M. A. (2014). Genetic improvement of purslane (Portulaca oleracea L.) and its future prospects. Mol Biol Rep, 41, 7395-7411. http://dx.doi.org/10.1007/s11033-014-3628-1

Chan, K., Islam, M. W., Kamil, M., Radhakrishnan, R., Zakaria, M. N., Habibullah, M., \& Attas, A. (2000). The analgesic and anti-inflammatory effects of Portulaca oleracea L. subsp. Sativa (Haw.) Celak. $J$ Ethnopharmacol, 73, 445-451. http://dx.doi.org/10.1016/S0378-8741(00)00318-4

Cotran, R. (2010). Acute and Chronic inflammation. Elsevier, PA, USA.

Ellulu, M. S., Khaza'ai, H., Abed, Y., Rahmat, A., Ismail, P., \& Ranneh, Y. (2015). Role of fish oil in human health and possible mechanism to reduce the inflammation. Inflammopharmacology,

El-Sayed, M. I. (2011). Effects of Portulaca oleracea L. seeds in treatment of type-2 diabetes mellitus patients as adjunctive and alternative therapy. $J$ Ethnopharmacol, 137, 643-651. http://dx.doi.org/10.1016/j.jep.2011.06.020

Farshori, N. N., Al-Sheddi, E. S., Al-Oqail, M. M., Musarrat, J., Al-Khedhairy, A. A., \& Siddiqui, M. A. (2014). Cytotoxicity assessments of Portulaca oleracea and Petroselinum sativum seed extracts on human hepatocellular carcinoma cells (HepG2). Asian Pac $J$ Cancer Prev, 15, 6633-6638. http://dx.doi.org/10.7314/APJCP.2014.15.16.6633

Gu, J. F., Zheng, Z. Y., Yuan, J. R., Zhao, B. J., Wang, C. F., Zhang, L., ... Jia, X. B. (2015). Comparison on hypoglycemic and antioxidant activities of the fresh and dried Portulaca oleracea L. in insulin-resistant HepG2 cells and streptozotocin-induced C57BL/6J diabetic mice. J Ethnopharmacol, 161, 214-223. http://dx.doi.org/10.1016/j.jep.2014.12.002

Kavazos, K., Nataatmadja, M., Wales, K. M., Hartland, E., Williams, C. \& Russell, F. D. (2015). Dietary Supplementation with Omega-3 Polyunsaturated Fatty Acids Modulate Matrix Metalloproteinase Immunoreactivity in a Mouse Model of Pre-abdominal Aortic Aneurysm. Heart Lung Circ, 24, 377-385. http://dx.doi.org/10.1016/j.hlc.2014.11.005

Koh, A. S., Pan, A., Wang, R., Odegaard, A. O., Pereira, M. A., Yuan, J. M., \& Koh, W. P. (2015). The association between dietary omega-3 fatty acids and cardiovascular death: the Singapore Chinese Health Study. Eur J Prev Cardiol, 22, 364-372. http://dx.doi.org/10.1177/2047487313517576

Lee, A. S., Kim, J. S., Lee, Y. J., Kang, D. G., \& Lee, H. S. (2012). Anti-TNF-alpha Activity of Portulaca oleracea in Vascular Endothelial Cells. Int $J$ Mol Sci, 13, 5628-5644. http://dx.doi.org/10.3390/ijms 13055628

Lee, S., Kim, K. H., Park, C., Lee, J. S., \& Kim, Y. H. (2014). Portulaca oleracea extracts protect human keratinocytes and fibroblasts from UV-induced apoptosis. Exp Dermatol, 23(Suppl 1), 13-17. http://dx.doi.org/10.1111/exd.12396

Li, Y., Hu, Y., Shi, S., \& Jiang, L. (2014). Evaluation of antioxidant and immuno-enhancing activities of Purslane polysaccharides in gastric cancer rats. Int $J$ Biol Macromol, 68, 113-116. http://dx.doi.org/10.1016/j.ijbiomac.2014.04.038

Liang, X., Li, L., Tian, J., Wu, Y., Gao, P., Li, D., ... Song, S. (2014). A rapid extraction and analysis method for the simultaneous determination of 26 bioflavonoids in Portulaca oleracea L. Phytochem Anal, 25, 537-543. http://dx.doi.org/10.1002/pca.2524

Liu, L., Howe, P., Zhou, Y. F., Xu, Z. Q., Hocart, C., \& Zhan, R. (2000). Fatty acids and beta-carotene in australian purslane (Portulaca oleracea) varieties. $J$ Chromatogr A, 893, 207-213. http://dx.doi.org/10.1016/S0021-9673(00)00747-0

Shen, H., Tang, G., Zeng, G., Yang, Y., Cai, X., Li, D., ... Zhou, N. (2013). Purification and characterization of an antitumor polysaccharide from Portulaca oleracea L. Carbohydr Polym, 93, 395-400. http://dx.doi.org/10.1016/j.carbpol.2012.11.107

Silva, R., \& Carvalho, I. S. (2014). In vitro antioxidant activity, phenolic compounds and protective effect against DNA damage provided by leaves, stems and flowers of Portulaca oleracea (Purslane). Nat Prod Commun, 9, 45-50. 
Simopoulos, A. P., Norman, H. A., \& Gillaspy, J. E. (1995). Purslane in human nutrition and its potential for world agriculture. World Rev Nutr Diet, 77, 47-74. http://dx.doi.org/10.1159/000424465

Simopoulos, A. P., Norman, H. A., Gillaspy, J. E., \& Duke, J. A. (1992). Common purslane: a source of omega-3 fatty acids and antioxidants. $J$ Am Coll Nutr, 11, 374-382. http://dx.doi.org/10.1080/07315724.1992.10718240

Simopoulos, A. P., Tan, D. X., Manchester, L. C., \& Reiter, R. J. (2005). Purslane: a plant source of omega-3 fatty acids and melatonin. $J$ Pineal Res, 39, 331-332. http://dx.doi.org/10.1111/j.1600-079X.2005.00269.x

Sturgeon, S. R., Volpe, S. L., Puleo, E., Bertone-Johnson, E. R., Heersink, J., Sabelawski, S., ... Kurzer, M. S. (2010). Effect of flaxseed consumption on urinary levels of estrogen metabolites in postmenopausal women. Nutr Cancer, 62, 175-180. http://dx.doi.org/10.1080/01635580903305342

Teixeira, M. C., Carvalho, I. S., \& Brodelius, M. (2010). Omega-3 fatty acid desaturase genes isolated from purslane (Portulaca oleracea L.): expression in different tissues and response to cold and wound stress. $J$ Agric Food Chem, 58, 1870-1877. http://dx.doi.org/10.1021/jf902684v

Truan, J. S., Chen, J. M., \& Thompson, L. U. (2010). Flaxseed oil reduces the growth of human breast tumors (MCF-7) at high levels of circulating estrogen. Mol Nutr Food Res, 54, 1414-1421. http://dx.doi.org/10.1002/mnfr.200900521

Uddin, M. K., Juraimi, A. S., Hossain, M. S., Nahar, M. A., Ali, M. E., \& Rahman, M. M. (2014). Purslane weed (Portulaca oleracea): a prospective plant source of nutrition, omega-3 fatty acid, and antioxidant attributes. Scientific World Journal, 2014, 1-6. http://dx.doi.org/10.1155/2014/951019

Varma, S., Eskin, M. N., Bird, R., Dolenko, B., Raju, J., Ijare, O. B., \& Bezabeh, T. (2010). Potential of magnetic resonance spectroscopy in assessing the effect of fatty acids on inflammatory bowel disease in an animal model. Lipids, 45, 843-854. http://dx.doi.org/10.1007/s11745-010-3455-7

Xin, H. L., Hou, Y. H., Li, M., Lu, J. C., \& Ling, C. Q. (2008). Alpha-linolenic acid and linoleic acid in extract of Portulaca oleracea L. determined by high-performance liquid chromatography. Zhong Xi Yi Jie He Xue Bao, 6, 1174-1177. http://dx.doi.org/10.3736/jcim20081113

Yang, Z., Liu, C., Xiang, L., \& Zheng, Y. (2009). Phenolic alkaloids as a new class of antioxidants in Portulaca oleracea. Phytother Res, 23, 1032-1035. http://dx.doi.org/10.1002/ptr.2742

Zhou, Y. X., Xin, H. L., Rahman, K., Wang, S. J., Peng, C., \& Zhang, H. (2015). L.: A Review of Phytochemistry and Pharmacological Effects. Biomed Res Int, 2015, 925631. http://dx.doi.org/10.1155/2015/925631

\section{Copyrights}

Copyright for this article is retained by the author(s), with first publication rights granted to the journal.

This is an open-access article distributed under the terms and conditions of the Creative Commons Attribution license (http://creativecommons.org/licenses/by/3.0/). 